\title{
GANGRENOUS PURPURA AND ITS OCCURRENCE IN MENINGOCOCCAL SEPTICAEMIA
}

\author{
BY \\ H. G. DUNN \\ From the Children's Department, The London Hospital
}

(Received for Publication July 6, 1950)

It is well-known that severe confluent purpura may result in death of the affected skin and subcutaneous tissues. This phenomenon, known as necrotic or gangrenous purpura, is, however, rare, and few cases have been recorded in this country. I wish to report the case of an infant who suffered and recovered from this condition, and also to discuss its aetiology and to describe the clinical features with special reference to the form encountered in meningococcal septicaemia.

\section{Case Report}

G.C. (No. 572 49), a boy, aged $4 \frac{1}{2}$ months, was admitted to The London Hospital in the evening of January 7,1949 . He was the third living child of healthy parents. Pregnancy and labour had been uneventful, and the birth weight had been $7 \mathrm{lb}$. The baby was breast fed and had been very well, though gaining weight excessively and now weighing nearly $18 \mathrm{lb}$. There had been no known contact with infections during the recent past.

During the night before admission the mother had noticed that the baby was restless, and at midnight he appeared feverish. He refused breast feeds but did not vomit. In the morning he screamed when picked up or touched. The mother then detected a few 'bruise spots' of variable size on the legs as well as one in the groin and scattered ones on the arms. In the afternoon the baby moaned continuously, and the rash spread and involved the face and trunk.

On admission, the infant was found to be big and obese, looking ill and pale, but not cyanosed, and crying persistently. The temperature was $102 \cdot 4^{\prime} \mathrm{F}$., the pulse rate 156 , and the respiration rate 50 per minute. There was a marked purpuric rash all over the body except on the palms, soles, and scalp. The individual lesions differed in size from a pinhead to 1 in. in diameter. They were biggest and most numerous on the buttocks where many had become confluent and formed ecchymoses, up to $2 \mathrm{in}$. in diameter and of irregular outline. The face, arms, and legs were moderately affected, the extensor and flexor aspects of the limbs being equally involved, while there were only a few lesions on the dorsa of hands and feet and on the trunk. The haemorrhagic areas felt firm, some of the smaller ones almost nodular. They were of a dull, port wine colour, and the larger lesions had a narrow erythematous border. In addition there was a faint pink mottling. more marked on the trunk than on the limbs.

The conjunctivae were congested, and the palpebral portions showed a few petechiae on both sides. Such spots were also noticed on the palate. The tongue was slightly furred and dry, the fauces were normal, and there was no glandular enlargement. The anterior fontanelle was open about $\frac{1}{2}$ in., and the tension was normal.

The infant was conscious, grasped and kicked strongly, but seemed very irritable. There was doubtful neck rigidity, but Kernig's test and Brudzinski's neck sign were negative, and there were no other abnormal physical signs in the nervous system or elsewhere. The urine showed a trace of albumin, but no other abnormality.

A diagnosis of meningococcal septicaemia was made.

Lumbar puncture was performed and showed faintly opalescent, colourless fluid at a pressure of $115 \mathrm{~mm}$. The cerebrospinal fluid contained 55 leucocytes per c.mm., protein $50 \mathrm{mg}$. \%, sugar $87.5 \mathrm{mg}$. \%, and chlorides $655 \mathrm{mg}$. ${ }_{\mathrm{o}}^{\circ}$. The deposit showed polymorphonuclears and lymphocytes in approximately equal numbers. Organisms were not seen and the fluid was sterile.

Nose and throat swabs were negative for meningococci. A blood count showed the haemoglobin to be $80^{\circ}$, the W.B.C. 22,100 per c.mm. with $74 \%$ polymorphonuclears, and platelets were plentiful in the film. The bleeding time was 2 minutes, and the clotting time 1 minute 52 seconds. One of the purpuric lesions on the buttocks was scarified, and a smear made from it showed a few intracellular Gram-negative cocci, morphologically resembling meningococci. Blood culture was not performed as internal jugular or anterior fontanelle puncture would have been required, and these were not considered advisable in view of the baby's critical condition and the presence of extensive haemorrhages.

At the time of lumbar puncture 5,000 units of penicillin were injected intrathecally, and this was repeated the next day. Penicillin, 25,000 units, and 'sulphamezathine soluble', 1 g., were also administered intramuscularly, and this was followed by penicillin 25,000 units intramuscularly 6 -hourly and 'sulphamezathine' (sulphadimidine) $0.5 \mathrm{~g}$. by mouth 4 hourly. The 


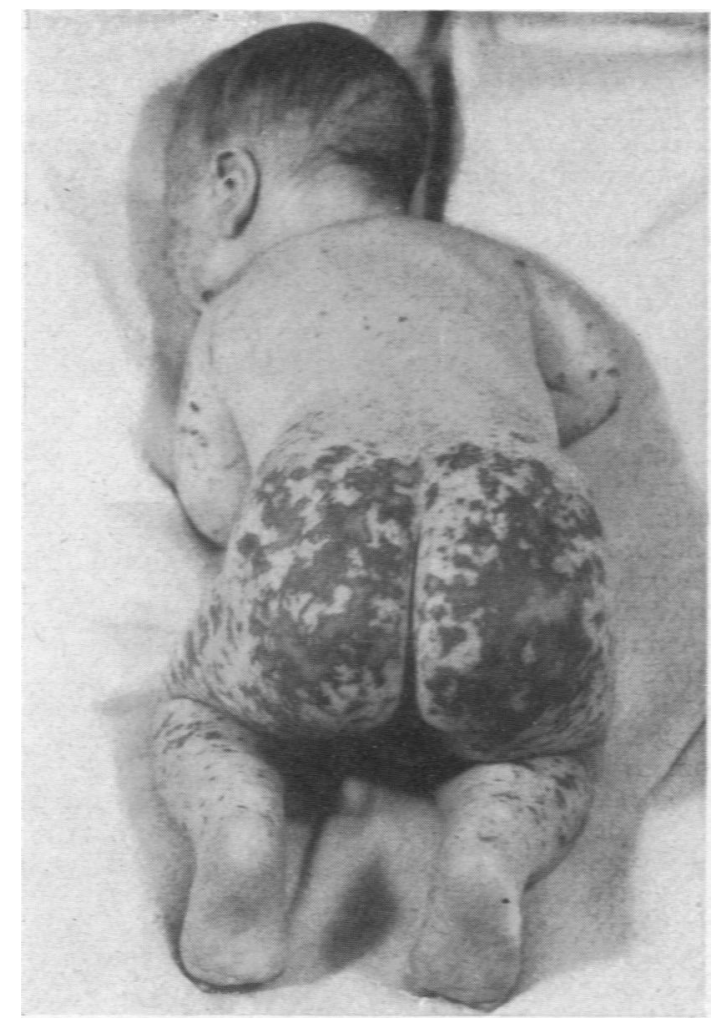

FIG. 1.-Patient on second day.

dosage of the latter was halved after 24 hours. Vitamin C (ascorbic acid $25 \mathrm{mg}$. b.d.) and vitamin $\mathrm{K}$ ('synkavit' $10 \mathrm{mg}$. intramuscularly daily) were also given.

The baby took fluids reluctantly from the bottle and remained restless during the night. The next morning (January 8) he appeared slightly dehydrated, and a gastric milk drip was set up. The rash had by now become more purple and intense, the relative distribution remaining unaltered. On the buttocks the lesions had become still more confluent (Fig. 1) and also raised into plaques, some of which now showed paler greyish and slightly softer centres. The legs felt firm and indurated. The infant made frequent sudden jerking movements of the limbs, and the spleen had become palpable. The temperature was still $101-103^{\circ} \mathrm{F}$.

Lumbar puncture on this day revealed clear colourless fluid at a pressure of $205 \mathrm{~mm}$. containing 70 leucocytes per c.mm., protein $40 \mathrm{mg}$. ${ }^{\circ}$, sugar $75 \mathrm{mg} .{ }^{\circ}$, and a sulphonamide level of $5.25 \mathrm{mg} . \%$, with a deposit of lymphocytes, a few cosinophils and occasional red blood cells. The fluid was again sterile.

On the third day (January 9) the tempcrature had fallen to $100-101^{\circ} \mathrm{F}$., and the infant's general condition was improved. The purpura had not spread any further, but the pale centres of the ecchymoses on the buttocks had softened to definite blisters, from some of which sanguineous fluid was seen to ooze. The infant was nursed on his side or prone, and the gastric drip was continued.

On the fourth day (January 10) the ecchymoses appeared less raised and the purpuric eruption generally appeared quiescent, while the erythematous mottling had disappeared. There was now a weeping area on the right buttock with a diameter of $\frac{1}{2}$ in., and there were flaccid blisters of similar size on the left.

On the fifth day (January 11) there were two additional blisters on the left buttock, while the legs felt softer. The child was not dehydrated any longer, and the gastric drip was discontinued and replaced by bottle feeds of expressed breast milk. A blood count showed haemoglobin $76^{\circ}$, W.B.C. 8,400 per c.mm. $\left(39^{\circ}{ }_{o}\right.$ polymorphonuclears, $60^{\circ}$ o lymphocytes, $1^{\circ} \%$ mononuclears), and a normal number of platelets in the film. Lumbar puncture revealed clear colourless fluid under a pressure of $110 \mathrm{~mm}$., containing 2 leucocytes per c.mm. and $40 \mathrm{mg}$. ${ }^{\circ}$ of protein. The dosage of penicillin was changed to 30,000 units 8-hourly intramuscularly, and of sulphadimidine to $0 \cdot 25 \mathrm{~g}$. 6-hourly.

On the sixth day (January 12) the purpuric lesions were beginning to heal, particularly on the face. Both buttocks were now oozing and were dressed with tulle gras.

On the seventh day the baby's condition was satisfactory but the temperature still continued to be

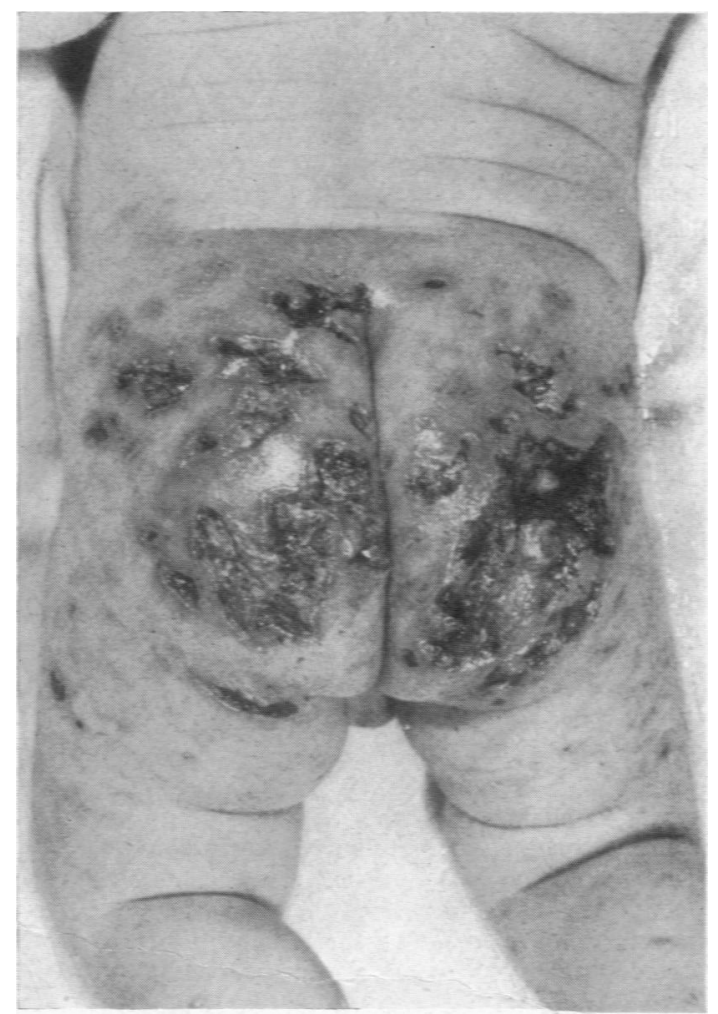

Frg. 2.-Patient on fifteenth day. 


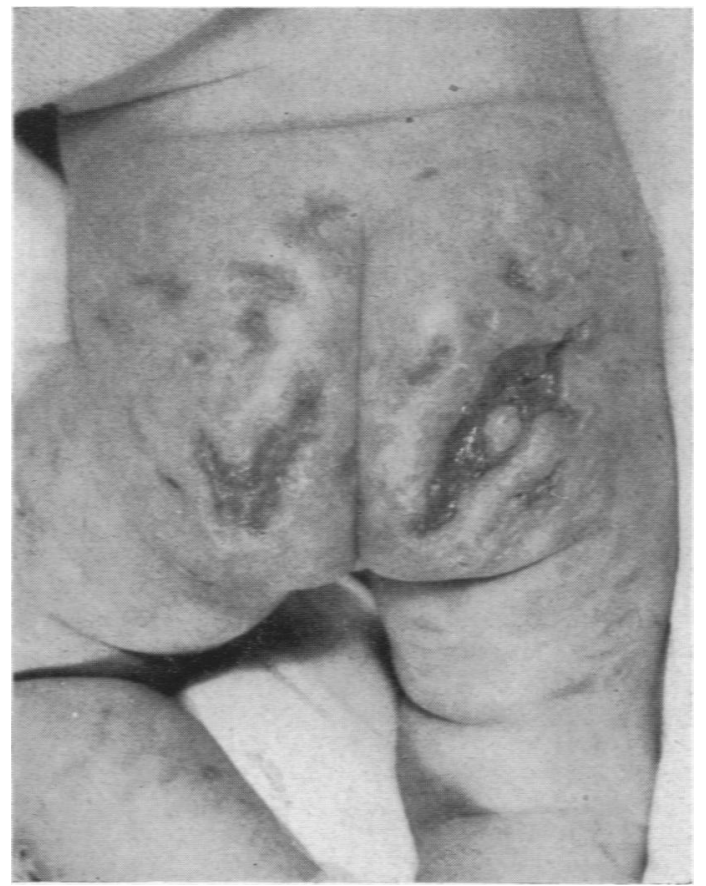

Fig. 3-Patient on twenty-ninth day.

100-101 = F. A blood culture was taken but proved sterile both aerobically and anaerobically.

On the eighth day breast feeding was begun again, and sulphadimidine therapy discontinued. The infant now weighed $17 \mathrm{lb} .11 \mathrm{oz}$.

By the tenth day the purpuric lesions were all healing, but on the buttocks there were now sharply circumscribed ulcers extending deeply into the subcutaneous tissues and containing soft haemorrhagic sloughs. These were covered with tulle gras, and with penicillin cream or subsequently penicillin-sulphathiazole powder, but they tended to become soiled by faeces. Systemic penicillin treatment was continued, but from the twelfth day was given orally $(20,000$ units 3 -hourly before feeds).

By the fourteenth day (January 20) the haemorrhagic sloughs on the buttocks were beginning to separate in the form of blackish-brown pieces of a jelly-like consistency. This left deep ulcers with sharp punched-out edges (Fig. 2). One piece of slough was examined bacteriologically: Proteus, Bact. coli, and a faecal streptococcus grew on culture. A blood count now showed haemoglobin $65^{\circ}$, W.B.C. 18,900 per c.mm. with $42^{\circ}$ o polymorphonuclears, slight anisocytosis and polychromasia, platelets being plentiful in the film.

The separation of sloughs was complete by the sixteenth day, and the base of the deep ulcers appeared fairly clean. The infant's general condition was good, and the weight was rising, while the canperature had fallen to $99^{\circ} \mathrm{F}$.

Two days later a swab taken from the ulcers on the buttocks still showed a moderate number of pus cells in the film but no organisms. Staphylococcus pyogenes and scanty Proteus were grown on culture; both proved insensitive to sulphonamides. Local treatment was therefore changed to eusol compresses. On this regime the ulcers epithelialized well and remained clean.

Oral penicillin was discontinued on the twenty-fifth day (January 31). The infant's further progress was complicated by an upper respiratory infection with gastroenteritis. Bilateral otitis media developed and required myringotomy on the thirty-fourth day (February 9). After that the baby made an uneventful recovery.

The buttocks healed satisfactorily (Fig. 3), and when the infant was discharged home on the forty-first day (February 16) there was only one moist, unepithelialized streak, about $\frac{1}{4} \times 1 \frac{1}{2}$ in. in size, on each side. He continued to be seen as an out-patient and did well.

A month after discharge his buttocks were fully healed though showing considerable scarring (Fig. 4).

A meningococcal complement fixation test was performed on the sixteenth day (January 22) and proved positive to a serum dilution of 1:10 with antigen from Group II meningococcus. Control tests with antigens from Group I meningococcus, gonococcus, and Micrococcus catarrhalis were negative. The test was repeated on the day of discharge (February 16) when it was weakly positive to meningococcus Group II antigen at a serum dilution of 1:5. Fifteen days later it was negative. The Wassermann reaction was also negative.

When last seen on December 6, 1949, 11 months after admission, the baby weighed $26 \mathrm{lb} .7 \mathrm{oz}$. and was quite well although he had suffered from frequent upper respiratory infections. There had been no further purpura or other haemorrhages.

To summarize: this was a case of widespread purpura of sudden febrile onset in an infant aged $4 \frac{1}{2}$ months. Gangrene supervened in areas of confluent purpura on both buttocks. The spread of haemorrhagic lesions was arrested and the constitutional disturbance ceased on treatment with penicillin and sulphadimidine. The buttocks healed with scarring after separation of the sloughs, and the baby made a full recovery.

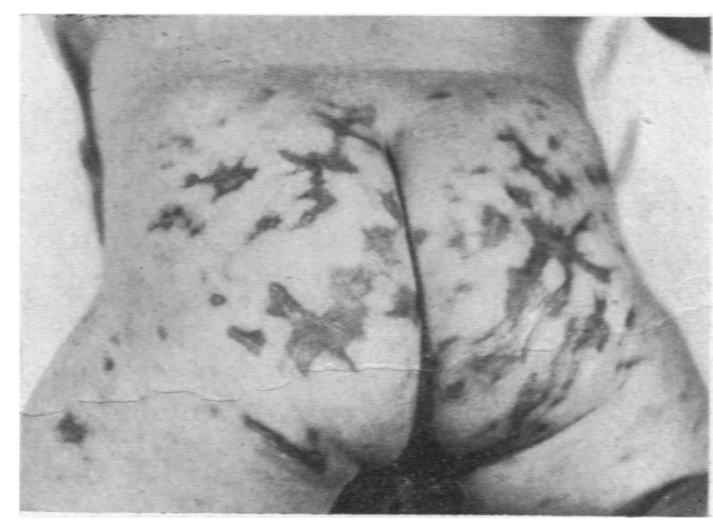

Fig. 4.-Patient on seventy-second day. 
The condition is thought to have been due to meningococcal septicaemia, for although the infecting organism was not isolated in culture, meningococci were inculpated by (1) the acute febrile onset with an erythematous rash accompanying purpura, (2) the raised cell count in the cerebrospinal fluid, probably indicating the onset of meningitis, (3) the finding of Gram-negative cocci, morphologically identical with meningococci, in a purpuric lesion, (4) the positive meningococcal complement fixation test on the sixteenth day of the disease with subsequent fall in titre.

\section{Aetiology of Gangrenous Purpura}

In his textbook ' On Cutaneous Diseases,' Robert Willan (1808) described 'purpura haemorrhagica, in a woman of 36 years, and stated that 'two spots on the back of the left hand terminated with gangrenous sloughs.' Other cases of purpura with necrotic changes were reported by a number of observers in the nineteenth century. The lesions varied from necrosis of patches of skin to complete gangrene of both feet (Warden, 1878). They were generally more marked on the limbs than on the trunk, the face was moderately involved, while the buttocks and feet were often particularly severely affected. Sometimes the gangrene was remarkably symmetrical; if healing occurred, it might take several months (Petri, 1879).

In some of those early cases the purpura was quite evidently symptomatic in the course of some other disease, such as typhus fever, haemorrhagic smallpox, chickenpox or scarlet fever and other exanthemata; or in certain cases of poisoning and of nutritional defect. It was also known that local pressure applied to purpuric lesions in general was easily followed by necrosis. But in the majority of cases the cause was quite obscure, and many authors thought that "purpura haemorrhagica gangraenosa' might be a disease sui generis.

In the Continental literature, Martin de Gimard (1888) is credited with being the first to have made a systematic study of this syndrome. In his thesis on 'primary haemorrhagic purpura' he is said to have described two cases with gangrene, a fatal one in a boy of 14 years of age, and a non-fatal one in a boy of 8 years. In the former he cultured a Gram-positive coccus from the blood, and by inoculating this organism into animals he produced purpuric lesions, in which he demonstrated the same cocci. He postulated a septicaemic process caused by this 'micrococcus purpurae' and an inflammatory reaction on the part of cutaneous vessels producing the haemorrhages. However, he evidently had to admit that his organism was difficult to isolate, and other workers were unable to verify his results, though they incriminated a variety of known bacteria.
Efforts to find the cause of this apparently primary gangrenous purpura continued but were hampered by the rarity of the condition. By 1896, Bürcher was able to collect 16 cases from the European literature and added one of his own, a girl aged $1 \frac{1}{2}$ years, with sudden febrile onset of extensive purpura and subsequent recovery. He emphasized the youth of the patients. Among 24 cases of this and related purpuric conditions, 21 occurred in the first three decades and 10 were in children aged 1 to 10 years.

In the present century, scanty cases are still recorded in which gangrenous purpura occurred purely symptomatically in some other disease, and it may be noted in passing that it appears to be found in temporary haemorrhagic states, as in polyarteritis nodosa (Freund, 1926) or intolerance to mussels (Dérot, Tanret and Brochen, 1948), rather than in the actual blood diseases. It would seem to be intimately associated with vascular damage while the clotting mechanism of the blood may be quite normal.

As to the "purpura gangraenosa" which had previously been thought to be a primary disease entity, bacteriological advances have revealed that the majority of cases are indeed septicaemic in origin as Martin de Gimard had thought, but a variety of organisms may be responsible. The most important one now is the meningococcus. In addition there are still some cases of obscure causation, which may be anaphylactoid in nature.

Septicaemic purpura in meningococcal infection will be discussed in detail below. Among the other organisms which may cause it, streptococci are outstanding. Chevallier (1937) indeed thought that these were the usual cause of gangrenous purpura. He emphasized that Martin de Gimard had isolated Gram-positive cocci, and he described a case of his own, a nurse aged 28 years, who had subacute bacterial endocarditis and whose blood culture showed a non-haemolytic streptococcus. The histology of purpuric skin lesions in this patient revealed a strongly haemorrhagic acute "panangeitis' of the terminal blood vessels of the skin. Rigal's (1880) case may well have been similar, as fever and gangrenous purpura supervened in a patient with rheumatic mitral stenosis and insufficiency. Beinhauer (1929) recorded deep purpuric gangrene of the lower limbs in a boy aged 2 years and 4 months who finally died of pneumonia and streptococcal septicaemia, but the initial aetiology was obscure. Michael's (1920) case of purpura with symmetrical gangrene of the fingers was suggestive of septicaemia, but no organism was isolated on blood culture.

Idiopathic cases without evidence of septicaemia 
or underlying primary disease are still described. Sometimes they occur during convalescence from acute fevers, such as measles or scarlet fever, but often there is no clue whatsoever as to the cause. Recently Sheldon (1947) reported three such cases in children and emphasized the anaphylactoid type of symptoms, viz. pains in the limbs (sometimes with joint swellings); subcutaneous swellings of eyelids, hands and feet; absence of fever and of polymorphonuclear leucocytosis. $\mathrm{He}$ also gave a detailed description of the purpuric rash, which differed little from gangrenous purpura in septicaemic cases like that reported above. Sheldon suggested that the 'purpura necrotica' which he described might be analogous to the Shwartzman phenomenon, in which haemorrhagic necrosis is produced at the site of an intradermal injection of bacterial filtrate by injecting the same filtrate intravenously some 24 hours later. The fact that disseminated gangrenous purpura has been described in the course of serum sickness in a boy recovering from scarlet fever (Lesné, Lefèvre, and Laffitte, 1922) might be taken as evidence in favour of the anaphylactoid nature of some of these cases.

Rebationship to Purpura Fulminans. The aetiology of apparently primary 'purpura gangraenosa' as described above is remarkably similar to that of purpura fulminans. The latter condition was first fully described by Henoch (1887) who recorded two cases of his own and summarized a third previously reported by Charron and a fourth communicated to him by Michaelis. All four were children, aged 9 months to 5 years, who suddenly developed rapidly spreading, confluent ecchymoses and died within 24 hours or at the most four days without having developed any complications. The haemorrhages were confined to the skin, and apart from one conjunctival petechia in one case the mucosae were not involved. Unless death supervened in 24 hours, blisters were noted to form on the ecchymoses, but the author insisted that gangrene did not develop. Necropsy findings were uniformly negative and failed to reveal the cause of the condition. Henoch admitted that the interpretation of these cases was obscure. A preceding infection (pneumonia and possible scarlet fever, respectively) had been present in the first two cases but not in the others.

Subsequently, occasional similar cases were recorded. By 1905, Risel was able to review 12, including one of his own, all in children aged 5 years or less. One of these (Borgen's case) was evidently due to streptococcal septicaemia, and thereafter improvements in bacteriological technique gradually revealed septicaemia as a frequent cause of the syndrome. It was also shown that the patients usually had a polymorphonuclear leuco- cytosis with a normal number of platelets and that the clotting mechanism of the blood was generally unimpaired.

Many distinguished authors concluded that purpura fulminans was simply a manifestation of hyperacute septicaemia in young children. This was also the opinion expressed by Hammer (1928) in a full review of the subject. Some consider the condition particularly characteristic of fulminating meningococcal or streptococcal purpura.

There are, however, others who state that the septicaemic cases do not represent the true purpura fulminans of Henoch at all. Certainly, examples of the condition with sterile blood culture and without other evidence of septicaemia have been recorded from time to time. Such cases were Risel's (1905) own which followed scarlet fever and also those described by Bischoff (1924), Morawitz (1926), and Knauer (1927). Morawitz thought that the remarkable symmetry of the lesions in these non-septicaemic cases might indicate an aggravation of vascular damage by an abnormality of vasomotor centres in the spinal cord, as had long been suggested by French authors. Rolleston (Rolleston and McCririck, 1910; Rolleston and Ronaldson, 1940) noted that a considerable proportion of the recorded cases of purpura fulminans had occurred during convalescence from scarlet fever. Finally Glanzmann (1937) emphasized that the condition usually arose in an 'anaphylactoid situation,' i.e., after infections such as pneumonia, measles, chickenpox, and scarlet fever. In a case of his own, a baby aged $6 \frac{1}{2}$ months who recovered, he stressed the symmetrical arrangement of ecchymoses and the fact that crops of purpura were accompanied by papules with urticarial borders and by pale inflammatory oedema of the feet. $\mathrm{He}$ found the platelets, clotting and bleeding times, clot retraction and plasma fibrinogen normal, he noted only slight leucocytosis ' without strong nuclear shift' (to the left), and stressed the occurrence of eosinophilia, especially in convalescence. He concluded that Henoch's purpura fulminans is only the most severe form of anaphylactoid purpura.

Thus it will be seen that the clinical syndrome of purpura fulminans like that of "purpura gangraenosa' has been attributed chiefly to septicaemia, but it may also occur in an idiopathic, possibly anaphylactoid, form.

As Chevallier (1937) has pointed out, the descriptions of purpura fulminans in the literature are on the whole very similar to the early stage of gangrenous purpura. If Henoch insisted on the absence of 'gangrene' he took that term in the sense of putrefaction, and there was not enough time in his cases for this or for sloughing to develop. 
Purpura fulminans and gangraenosa may now indeed be linked together as different forms of the same condition, and if the former ceases to spread it may change into the latter.

\section{Gangrenous Purpura in Meningococcal Septicaemia}

Meningococcal septicaemia was not recognized as a cause of gangrenous purpura until the 1914-18 war, when the infection was prevalent, especially among soldiers and children. Instances in the British literature are the cases reported by Gardner Robb (1916) and by Elliott and Kaye (1917). The latter described a soldier who had meningitis and necrotic purpura complicated by trench feet. They pointed out that purpura in cerebrospinal meningitis was rarely followed by necrosis, partly perhaps for the reason that severe purpura was usually associated with so overwhelming an infection that death ensued before the local necrotic changes could occur. In France, Blanchier (1918) described 16 cases of meningococcal purpura in children, only one of whom developed gangrenous changes. This was a boy of 6 months who was treated with antimeningococcal serum but developed iridocyclitis, arthritis of both elbows, and erysipelas and finally died.

Recently meningococcal infection has figured most prominently in the scanty case-records of gangrenous purpura. This is probably due to the fact that patients with fulminating meningococcal septicaemia and extensive purpura may now survive owing to the prompt administration of chemotherapy and will thus have time to develop local necrotic changes. In France, Poinso, Claudo, Aubanel, and de Balmann (1939) reported the case of a girl who had meningococcal meningitis and gangrenous purpura and who recovered on treatment with a sulphonamide, anti-meningococcal serum, vitamin $A$, and small blood transfusions; the photographs of this patient are reminiscent of our own. In 1946 Marie, Seringe, Cousin, and Marie added three cases, all below 3 years of age, who recovered on treatment with sulphonamides and anti-meningococcal serum.

In the United States, Thomas (1943) described an outbreak of meningococcal infection among troops which involved 1,935 cases with 64 deaths. He mentioned that four patients had large sloughs involving the skin and subcutaneous tissues in confluent purpuric areas; so this represented a rare complication. Hill and Kinney (1947) record gangrenous purpura of the extremities in two patients recovering from acute ' meningococcaemia.' In one of these, necrosis of the entire toes occurred and amputation was necessary. De Fuccio and Dresner (1949) report that bilateral amputation of the feet was required in a Negro boy treated with sulphadiazine and intrathecal and intramuscular penicillin. A similar occurrence in a woman of 27 years is related by Hayes and Whalen (1945), but the meningococcal aetiology does not appear to have been proved. Bernstein (1944) described the case of a 34-year-old woman with meningococcal meningitis who developed purpuric dry gangrene of the toes and of scattered areas of the skin and also causalgia along the distribution of the right ulnar nerve. In this country, Banks (1948) in his review of meningococcal disease, mentions that ulcers of the skin and subcutaneous tissue occasionally result from the breaking down of massive purpuric lesions and that scarring may result, but he gives no details.

Adding our own case to those just quoted and omitting those which are not fully described or proven, we are left with ten patients as follows.

\begin{tabular}{|c|c|c|c|}
\hline Author & Sex & Age & Course and Complications \\
\hline $\begin{array}{l}\text { Gardner Robb } \\
\text { (1915) }\end{array}$ & $\mathbf{M}$. & 'Young man' & $\begin{array}{l}\text { Meningitis and ophthalmia. } \\
\text { Recovered with loss of } \\
\text { one eye. }\end{array}$ \\
\hline $\begin{array}{l}\text { Elliott and } \\
\text { Kaye (1917) }\end{array}$ & $\mathbf{M}$. & 23 & $\begin{array}{l}\text { Meningitis. Slow healing } \\
\text { of gangrenous areas on } \\
\text { thighs. Recovery after } \\
\text { amputation of frost-bitten } \\
\text { (gangrenous) feet. }\end{array}$ \\
\hline Blanchier (1918) & M. & 6 months & $\begin{array}{l}\text { Died after development of } \\
\text { right iridocyclitis, arth- } \\
\text { ritis of elbow's and ery- } \\
\text { sipelas. }\end{array}$ \\
\hline $\begin{array}{l}\text { Poinso et al. } \\
\text { (1939) }\end{array}$ & $\mathbf{F}$. & 3 & $\begin{array}{l}\text { Meningitis. Recovered. } \\
\text { Right otorrhoea during } \\
\text { convalesence. }\end{array}$ \\
\hline Bernstcin (1944) & F. & 34 & $\begin{array}{l}\text { Meningitis. Recovered } \\
\text { after amputation of gan- } \\
\text { grenous toes. Causalgia } \\
\text { right arm. }\end{array}$ \\
\hline $\begin{array}{l}\text { Marie et al. } \\
\text { (1946) }\end{array}$ & F. & 2 & $\begin{array}{l}\text { Meningitis. Recovered. } \\
\text { Extensive herpes simplex. }\end{array}$ \\
\hline$n$ & $\mathbf{M}$ & $\begin{array}{l}1 \text { year } 10 \text { months } \\
2 \text { years } 3 \text { months }\end{array}$ & $\begin{array}{l}\text { Meningitis: Recovered } \\
\text { ? right basal poenmonia. } \\
\text { Recovered. }\end{array}$ \\
\hline $\begin{array}{l}\text { DeFuccio and } \\
\text { Dresner (1949) }\end{array}$ & $\mathbf{M}$. & 7 & $\begin{array}{l}\text { Meningitis. Recovered } \\
\text { after amputation of both } \\
\text { feet. }\end{array}$ \\
\hline Present case & $\mathbf{M}$. & $4 \frac{1}{2}$ months & $\begin{array}{l}\text { Recovered. Bilateral otitis } \\
\text { media and gastro-enteritis } \\
\text { in convalescence. }\end{array}$ \\
\hline
\end{tabular}

Sex and Age Incidence. This series of ten cases is too small for detailed analysis, but it will be seen that the sexes are approximately equally affected (six male, four female), that the oldest patient was aged 34 years while ours was the youngest at $4 \frac{1}{2}$ months, and that seven of the 10 patients were children, six being aged 3 years or less and two being infants under 1 .

In this connexion it may be remembered that the incidence of meningococcal infection in general declines after the age of 25 , that it falls most heavily on children under 5 years old, and that there are far 
more cases in infants under the age of 1 than in any other single year of age (Banks, 1948).

Pathology and Pathogenesis. The histology of meningococcal purpura was first studied by German pathologists in the 1914-18 war. It was shown that the characteristic lesions were inflammatory in nature and affected the blood vessels. Haemorrhagic infiltrations in the dermis were found to centre around small inflammatory foci consisting chiefly of polymorphonuclear cells and encircling small vessels, especially arterioles. These infiltrations may be widespread and split the elements of the dermis and extend into the subcutaneous tissues. The arterioles show inflammatory and haemorrhagic changes of their coats and may exhibit hyaline and cellular thrombi obliterating the lumen or, rarely, even total necrosis of the wall. In gangrenous purpura the typical inflammatory-haemorrhagic lesions are found along the edges of the plaque while the centre consists of a necrotic mass involving not only the dermis but also the subcutaneous tissues. The epidermis is then also infiltrated by red blood cells up to the stratum granulosum or even the corneum, and, owing to accompanying oedema, is lifted up into blisters and finally shares in the necrotic process. Gram-negative diplococci may occasionally be found in the arterioles and in the extravascular exudate. Marie et al. (1946) performed skin biopsies in their three cases of gangrenous purpura and found essentially the same lesions. The early changes were followed by necrosis and subacute inflammatory ulceration and finally by fibrosis of the deeper parts of the dermis and of the subcutaneous tissues. Gram-negative diplococci were demonstrated in the skin sections of one of their patients. Hill and Kinney (1947), studying necropsy material, found meningococci in the endothelial cells of small blood vessels and capillaries and also in the cytoplasm of many leucocytes.

We may conclude that the skin lesions can be explained on the basis of vascular damage resulting from the presence of meningococci which injure the endothelium and cause inflammation of the vessel walls with consequent necrosis, thrombosis, and extravasation. However, this damage may be, at least partly, an effect involving sensitization. Shwartzman (1928) demonstrated in rabbit experiments that meningococcal culture filtrate could produce the phenomenon since named after him. The filtrate was inoculated intradermally, and this was followed by an intravenous injection of the same substance 24 hours after. Within three to four hours of the second (or provocative) injection the skin at the site of preparation became haemorrhagic and then necrotic. This experiment has been extended by Black-Schaffer, Hiebert, and Kerby (1947) who produced the same Shwartzman phenomenon by using washed meningococci, both living and dead. Strains obtained from human purpuric cases were more active than those from patients suffering from meningitis without purpura.

It has been mentioned already that a form of the Shwartzman phenomenon has been suggested as the underlying process in the idiopathic form of gangrenous purpura (Sheldon, 1947), and it would seem quite possible that some such mechanism forms the connecting link among most, if not all, forms of severe purpura with necrosis.

Bacteriology. In epidemics of cerebrospinal fever, meningococci of Group I (Gordon's types I and III) are found much more commonly than those of Group II (Gordon's types II and IV). Both groups, however, are pathogenic, and in rabbits the ability to produce purpura was shown to bear no relation to the serological group of the organisms (Black-Schaffer et al., 1947).

While Group I ('Meningococcus A') was held responsible for the gangrenous purpura in Poinso"s (Poinso, Ciaudo, Aubanel, and de Balmann, 1939) patient, Group II was inculpated in the second case of Marie et al. (1946), in that of De Fuccio and Dresner (1949), and in ours.

Symptomatology. It is not intended here to describe acute meningococcal septicaemia in detail. There will be symptoms and signs of an acute infection of sudden onset. Signs of meningitis and even of encephalitis or adrenal involvement may be present (see Banks, 1948).

Characteristically, the skin will reveal not only the purpura, which we are to discuss further, but also other rashes. These are of diverse types, and different lesions may be present simultaneously. In the early stages, the commonest are erythematous macules, about $2 \mathrm{~mm}$. to $1 \mathrm{~cm}$. in diameter, which may appear rubelliform or may simulate the rosespots of typhoid fever; they are found chiefly on the trunk and legs. Papular, nodular, and vesicular lesions have also been described. Some of the erythematous areas and papules may have purplish haemorrhagic centres, and the larger ones are nearly always palpable and may resemble erythema nodosum. Herpes febrilis of extensive and atypical distribution, so common in cerebrospinal fever in adults, is rare in children under 3 years.

Purpura is present in the majority of cases of acute meningococcal septicaemia, and may be very extensive. The individual lesions vary in size from pinhead petechiae to large blotches and extravasations covering whole segments of the body. They are usually firm and indurated, so that the smaller ones feel shotty or nodular, while the larger 
ecchymoses form distinct plaques. Marie et al. (1946) have described 'lead shot' (grain de plomb) nodules in the skin with or without overlying visible purpura. The larger extravasations have a perfectly clear outline forming an irregular 'geographical' pattern, which has often been likened to an ink-spot extended by folding a sheet of paper around it.

As regards the distribution of the purpuric lesions, it is striking that the buttocks were severely affected in all the recorded cases of gangrenous purpura in babies. In older children and adults the feet, particularly the toes, are often the sites of predilection. The rest of the lower limbs, arms and face (including ears) are also frequently involved at all ages. The trunk, neck, and scalp are less commonly affected by large purpuric lesions, and the mucous membranes are relatively free, though isolated spots may be found in the mouth and conjunctival sacs. Generally, sites of trauma and pressure are likely to show purpura, e.g. the point of the elbow, or skin anywhere compressed by strapping. In infants, pressure may well explain both the predilection for the buttocks and the absence of complete symmetry.

The lesions of gangrenous purpura are initially port wine colour, and they frequently show an erythematous, and sometimes oedematous, border. Subsequently their colour darkens to purple and violet. Blisters form on the surface and eventually burst discharging serous or sanguineous fluid. Finally, the whole plaque becomes bluish-black or violet-black from gangrenous ischaemia and sharply demarcated from the surrounding healthy skin. The eschar is usually confined to skin and subcutaneous tissues; when it separates it leaves a raw granulating surface which heals with considerable scarring. Following Marie et al. (1946) one may describe four phases in this evolution: (1) phase of appearance and generalization-48 hours; (2) phase of necrosis-four to five days; (3) phase of separation of sloughs-second to fourth weeks; (4) phase of repair-fifth to eighth weeks.

The smaller lesions usually fade without leaving residual signs, but they may form a purplish crust which drops off and may leave a tiny scar or light brown pigmentation.

Haematology. A polymorphonuclear leucocytosis is nearly always present; the bleeding and clotting times, platelet count, and clot retraction are usually within normal limits, though some initial abnormalities have been reported.

Diagnosis. Some of the general clinical features will suggest the presence of acute meningococcal septicaemia in cases of purpura. Such features are the co-existence of other erythematous skin rashes, of meningitis or of localized muscle and joint pains. Some authors have held that certain aspects of the purpura itself indicate a meningococcal aetiology. e.g. rapid development of vesicles or gangrene (Blanchier, 1918), perfect distinctness of outline and induration of lesions (Marie et al., 1946), or the presence of irregular rounded haemorrhages with gun-metal coloured centres (Hill and Kinney, 1947).

However, the only reliable diagnostic proof is the demonstration of meningococci as the cause of the disease. This can be carried out in several ways.

(1) By finding them in the purpuric lesions: the organisms may be shown promptly and simply in a smear taken from vesicles on the surface of purpuric plaques (Netter and Salanier, 1917) or in smears of serum from a scarified purpuric lesion (Netter, Salanier and Wolfrom, 1917), as in our case. Occasionally they can be cultured from fluid thus obtained. They can also sometimes be found in skin biopsies, but this method is rarely practised.

(2) By finding them in the blood: in severe infections it may be possible to demonstrate organisms in a direct blood smear. More commonly. they are grown by blood culture; this proves the diagnosis but it takes time.

(3) By finding them in the cerebrospinal fluid: this is usually possible in the presence of purulent meningitis and sometimes even in its absence. When the organisms are scanty in the deposit they may yet be grown on culture.

(4) Indirectly by serological tests: the complement-fixation test was used in our case. De Fuccio and Dresner (1949) obtained a positive precipitation reaction between fluid from their patient's bullae and anti-meningococcal serum. Others have used the meningococcal agglutination test.

In the differential diagnosis other septicaemic purpuras have to be considered first, especially those due to streptococci, pneumococci, and $H$. influenzae. which may all produce meningitis. The clinical features may differ in the points of detail already mentioned, and there may be an obvious primary focus like endocarditis, but only bacteriological investigation will prove the aetiology. Nonsepticaemic idiopathic purpura may also be extensive and gangrenous. This is distinguished by the frequent history of preceding acute exanthem, by anaphylactoid features, and by the absence of signs of acute infection and of bacteriological proof of septicaemia. Purely symptomatic gangrenous purpura in the course of some other illness is characterized by the features of the primary disease, be it infective, toxic, or nutritional. The relationship to purpura fulminans has already been discussed. and the aetiological similarity to purpura gangraenosa has been emphasized; meningococcal purpura may frequently begin in a fulminating manner and become gangrenous later. 
Prognosis. It was emphasized by observers as far back as in the First World War that the purpuric forms of meningococcal infection generally carry a graver prognosis than the others. Widespread and fulminating purpura was considered a particularly serious sign usually indicating an early fatal termination.

With the advent of chemotherapy the prognosis of all forms has improved, but severe purpura is still of serious import, particularly in infants. It may be noted here that in meningococcal infection in general, Harries (1942), using sulphonamide therapy, still found a mortality rate of $30 \cdot 8^{\circ}$ at 3 to 6 months of age.

The critical period now in fulminating meningococcal septicaemia is the first 24 hours. During this time, death, in spite of treatment, may occur from encephalitis or from overwhelming septicaemia which may be associated with adrenal haemorrhage. After survival for $\mathbf{4 8}$ hours the prognosis will have improved considerably, and necrosis will then have had time to become apparent in the purpuric areas. Hence gangrenous purpura is now usually a phenomenon seen in recovering patients.

Treatment. In all types of gangrenous purpura treatment must be given primarily for any underlying causative condition. Thus in the present form the meningococcal septicaemia has to be treated first, and as this will be acute or even fulminating, both penicillin and sulphonamides should be administered as soon as possible, and at least the initial dose of the latter given parenterally.

If there are signs of suprarenal involvement and peripheral vascular failure, oxygen and injections of adrenal cortical extract are also required. In these cases, transfusion of glucose-saline or plasma is usually indicated, and sulphonamides, penicillin, and adrenal extract may then be given intravenously in the transfusion fluid. Great care must, however, be exercised not to overload the failing circulation; also the pressure of splint and strapping on the limb may lead to local necrotic purpura. The use of plastic tubing in the vein which allows for greater mobility of the limb during transfusion may obviate the latter difficulty.

In France anti-meningococcal serum is still used in addition to chemotherapy in acute meningococcal septicaemia. Theoretically this would appear a sound procedure, but in practice its value seems doubtful.

Apart from specific treatment, the general management and nursing are of the utmost importance. The maintenance of fluid balance and of nutrition are of particular concern in children. The local treatment of gangrenous purpura aims at the prevention of further damage by pressure and by secondary infection. The patient must be nursed in a position avoiding pressure on the purpuric lesions, and these must be kept clean and covered with sterile dressings. Various antibiotics or antiseptics may be necessary to prevent or eliminate secondary infection.

The separation of sloughs should be assisted in order to obtain clean and granulating ulcers. The organisms growing in these are liable to be insensitive to sulphonamides and penicillin, as these drugs will have been used for systemic treatment. The choice of a suitable application will depend on the bacterial flora, but flavines, propamidine, or eusol may be found effective. With extensive necrosis the resultant ulcers may require skin grafting, and in some of the recorded cases amputations of fingers, toes or feet have had to be performed.

\section{Summary}

The occurrence of gangrenous purpura with recovery is described in an infant aged $4 \frac{1}{2}$ months.

The aetiology of the condition is discussed. It is concluded that gangrenous purpura is not a disease sui generis, but may have a number of known causes, though an idiopathic, possibly anaphylactoid, form is also still reported. Among the recognized causes septicaemia now appears the commonest and particularly that due to meningococcal infection. This was held responsible in the case described.

It is pointed out that the apparently primary forms of gangrenous purpura ("purpura gangraenosa ') have a similar aetiology to that of purpura fulminans, and that the former may often develop from the latter, particularly if specific therapy is applied.

The features of gangrenous purpura in meningococcal septicaemia are discussed in detail. Sensitization as in the Shwartzman phenomenon may play a part in the pathogenesis of the vascular lesions which are responsible for the purpura in this disease. Such a mechanism may form a connecting link among the severe types of purpura with necrosis in various conditions.

I wish to thank Dr. K. H. Tallerman, M.C., for permission to publish this case and for his encouragement and advice. My thanks are also due to Dr. A. E. Wilkinson for performing the meningococcal complement-fixation tests, to Dr. H. B. May and his staff for all the other laboratory investigations, to Miss Daphne Marshall for the photographs, and to Dr. E. H. Back and Dr. F. W. Nash for their help and criticism.

\section{REFERENCES}

Banks, H. S. (1948). Lancet, 2, 635, 677.

Beinhauer, L. G. (1929). Amer. J. Dis. Child., 38, 1013. Bernstein, P. (1944). New Engl. J. Med., 230, 482. 
Bischoff, H. (1924). Mschr. Kinderheilk., 28, 481.

Black-Schaffer, B., Hiebert, T. G., and Kerby, G. P. (1947). Arch. Path., 43, 28.

Blanchier, D. E. (1918). 'Les formes purpuriques de la méningococcémie.' Thèse de Paris.

Bürcher, E. (1896). 'Ueber Purpura haemorrhagica gangraenosa.' Inaugural Dissertation, Basel.

Chevallier, P. (1937). Sang., 11, 337.

DeFuccio, C. P., and Dresner, E. E. (1949). Pediatrics, 3, 837.

Dérot, M., Tanret, P., and Brochen, G. (1948). Bull. Soc. méd. Hôp. Paris, 64, 76.

Elliott, T. R., and Kaye, H. W. (1917). Quart. J. Med., 10,361

Freund, F. (1926). Arch. Derm. Syph., Wien, 152, 158.

Glanzmann, E. (1937). Schweiz. med. Wschr., 67, 829.

Hammer, F. (1928). 'Hämorrhagische Krankheiten,' in Jadassohn, J.: Handbuch der Haut-und Geschlechtskrankheiten. Berlin, Julius Springer, vol. 6, pt. 2, p. 512.

Harries, G. E. (1942). Brit. med. J., 2, 423.

Hayes, J. M., and Whalen, J. F. (1945). J. Amer. med. Ass., 127, 645.

Henoch (1887). Berl. Klin. Wschr., 24, 8.

Hill, W. R., and Kinney, T. D. (1947). J. Amer. med. Ass., 134, 513.

Knauer, H. (1927). Jb. Kinderheilk., 118, 1.

Lesné, Lefevre, and Laffitte (1922). Bull. Src. Pédiat. Paris, 20, 276.
Marie, J., Seringe, P., Cousin, M., and Marie, S. J. (1946). Sem. Hôp. Paris, 22, 326.

Martin de Gimard, J. L. A. (1888). 'Du Purpura hémorrhagique primitif.' Thèse de Paris. Quoted by Bürcher, 1896, Chevallier, 1937, and Marie et al., 1946.

Michael, M. (1920). Amer. J. Dis. Child., 20, 124.

Morawitz, P. (1926). Münch. med. Wschr., 73, 1558.

Netter, A., and Salanier, M. (1917). Brit. J. Child. Dis., $14,101$.

- 1 , and Wolfrom (1917). Ibid., p. 104

Petri (1879). Berl. klin. Wschr., 16, 509.

Poinso, R., Ciaudo, P., Aubanel, J., and De Balmann, A. (1939). Bull. Soc. méd. Hôp. Paris, 55, 891.

Rigal, (1880). Un. méd., 29, 55, 74, 85.

Risel, H. (1905). Z. Klin. Med., 58, 163

Robb, A. Gardner (1916). Proc. Roy. Soc. Med., Ther. and Pharm. Sect., 9, 5.

Rolleston, J. D., and McCririck, T. (1910). Brit. J. Child. Dis., 7, 58.

Diseases,' 3rd ed., p. $284 . \quad$ London.

Sheldon, J. H. (1947). Archives of Disease in Childhood, 22, 7.

Shwartzman, G. (1928). Proc. Soc. exp. Biol., N.Y., 26, 207.

Thomas, H. M. Jr. (1943). J. Amer. med. Ass., 123, 264.

Warden, C. J. W. (1878). Indian med. Gaz., 13, 71.

Willan, R. (1808). 'On Cutaneous Diseases,' vol. I, p. 459. London. 